\title{
PENGEMBANGAN APLIKASI BACKUP DAN RESTORE SECARA AUTOMATISASI MENGGUNAKAN SDLC UNTUK MENCEGAH BENCANA
}

\author{
Johanes Fernandes Andry \\ Program Studi Sistem Informasi, Universitas Bunda Mulia, Jakarta \\ jandry@bundamulia.ac.id
}

\begin{abstract}
ABSTRAK
Bagi para pengguna komputer baik individu maupun organisasi apalagi yang sehari-hari sering bekerja dan menyimpan data-data di dalam komputer, selalu harus waspada terhadap komputer yang tiba-tiba disaster atau karena kegagalan sistem. Jika tiba-tiba komputer yang digunakan disaster, akan menyebabkan data-data atau file yang berada di dalamnya hilang. Langkah backup sangat dibutuhkan untuk mencegah hilangnya data-data ketika komputer sedang disaster. Untuk melakukan backup data dapat dilakukan dengan berbagai cara seperti menggunakan cara online atau offline. Untuk cara offline dapat dilakukan dengan menggunakan aplikasi. Paper ini mengusulkan sebuah aplikasi untuk mengotomatisasi proses backup dan restore secara otomatisasi serta memastikan secara terus menerus data tersimpan dengan baik dan aman. Development dari aplikasi ini menggunakan SDLC Water Fall, yang terdiri dari requirement, analisa, design, coding, testing, implementasi dan maintenance. Dengan terbentuknya aplikasi backup dan restore, hasil penelitian berguna untuk membantu individu maupun organisasi terhindar oleh kegagalan sistem atau disaster lainnya, sehingga diharapkan dapat menekan biaya apabila terjadi kerusakan pada file ataupun data di komputer client maupun server. Simpulan dari penelitian ini yaitu backup harus dilakukan secara berkala dan berkelanjutan agar supaya tidak kehilangan data atau informasi yang nantinya akan berdampak buat individu maupun organisasi, sehingga terhindar oleh kegagalan sistem atau disaster lainnya. Aplikasi backup dan restore secara otomatitasi telah dapat melakukan backup dengan baik, jika melakukan konfigurasi selama 1 menit, dengan file atau folder yang besar, maka akan dapat menghambat kinerja dari computer, karena backup yang dilakukan dengan cara full backup.
\end{abstract}

Kata kunci: Aplikasi, Backup, Restore, Disaster, SDLC Water Fall.

\section{PENDAHULUAN}

Salah satu harta terpenting didalam dunia $I T$ adalah data. Data biasanya dapat digunakan kembali walaupun sudah beberapa lama tidak dipakai, dan oleh karena itu penyimpanan data merupakan suatu masalah serius yang harus diperhatikan (Wijaya, Robet \& Robin, 2015). Data dan informasi adalah beberapa hal yang menjadi krusial dalam pemulihan disaster atau bencana. Sebuah sistem yang berjalan pada suatu instansi atau organisasi akan bergantung pada informasi dan aplikasi yang memproses informasi tersebut. Informasi merupakan salah satu kebutuhan manusia yang paling dasar. Sebelum kita bisa menikmati sebuah informasi, maka kita memerlukan data (Afif, 2013).

Organisasi modern dari berbagai ukuran kecil, menengah dan besar mempertimbangkan bahwa informasi sebagai salah satu yang paling penting dari aset mereka yang harus diamankan terhadap meningkatnya jumlah ancaman [Aldasouqi \& Awajan, 2011]. Kebanyakan harta yang penting dalam dunia adalah data, dan oleh karena itu penyimpanan data merupakan masalah serius yang harus diperhatikan (Wijaya, Robet \& Robin, 2015).). Sebagian besar organisasi sekarang memiliki kesadaran yang lebih besar dari berbagai jenis gangguan usaha atau bisnis (Hoong \& Marthandan, 2014), dan mereka fokus pada perencanaan untuk kelangsungan bisnis, memastikan bisnis yang tangguh dan menggunakan pemulihan yang cepat setelah disaster atau bencana (Virgona, 2010). 
Sebuah rencana pemulihan bencana adalah mirip dengan polis asuransi yang memberikan perlindungan yang menyeluruh dari bencana alam, seperti gempa bumi, banjir, badai, dan tornado. Rencana pemulihan bencana selama bertahun-tahun yang biasanya digunakan oleh organisasi yang memiliki komputer dan data untuk operasi bisnis sehari-hari. Proses perencanaan pemulihan adalah mahal, sebuah alternatif adalah untuk backup data dari komputer dan menyimpannya di alternatif lokasi (Hawkins, Yen \& Chou, 2000). Backup merupakan sebuah proses penduplikasian data ke dalam media yang terpisah. Data hasil duplikasi tersebut nantinya akan digunakan untuk memulihkan kembali data bila terjadi kerusakan atau kehilangan data. Backup biasanya digunakan dengan dua tujuan utama yaitu:

- Untuk memulihkan kembali data yang mengalami kerusakan/kehilangan pada saat terjadi bencana.

- Untuk memulihkan sebagian kecil data yang mengalami kerusakan atau kehilangan akibat kesalahan manusia.

Jenis - jenis strategi backup adalah sebagai berikut:

- Snapshot backup, data diduplikasi secara live dengan melakukan penguncian terhadap seluruh data untuk sementara waktu dan kemudian dilakukan snapshot terhadap data tersebut yang dilanjutkan dengan dilepas agar dapat beroperasi kembali.

- Full backup, data diduplikasi secara keseluruhan baik data yang sudah pernah diduplikasi maupun belum pernah kedalam media yang terpisah. backup dilakukan secara berkala.

- Differential backup, data yang diduplikasi hanya merupakan data dilakukan marking. Backup dilakukan secara berkala.

- Incremental backup, Data yang diduplikasi hanya data yang belum pernah dilakukan backup. Bila terjadi perbedaan byte pada data, maka hanya perbedaan dari byte data tersebut yang akan diduplikasi. Backup dilakukan secara berkala.

- Continuous backup, Data dilakukan duplikasi secara terus menerus terhadap seluruh data yang berubah (Afif, 2013).

Penelitian sebelumnya tahun 2015 yang dilakukan oleh Edi Wijaya, Robet, dan Robin, tentang Perancangan Sistem Otomatisasi Backup Data Menggunakan File Transfer Protocol Berbasis Jaringan LAN (Studi Kasus Pada STMIK TIME Medan), telah dihasilkan kesimpulan sebagai berikut Aplikasi "Auto Bot" tidak memiliki pilihan waktu backup kepada user dan backup data hanya dapat dilakukan setiap satu jam sekali sehingga data yang sama akan di-backup setiap jamnya, hal ini memberikan beban pada komputer client dalam hal pemakaian memory harddisk.

\section{METODE PENELITIAN}

Manfaat dari penelitian ini diharapkan dapat membantu membantu individu maupun organisasi terhindar oleh kegagalan sistem atau disaster lainnya, sehingga diharapkan dapat menekan biaya apabila terjadi kerusakan pada file ataupun data di komputer client maupun server.

Metode penelitian yang dirancang dengan SDLC yaitu System Development Life Cycle Model Waterfall. SDLC merupakan siklus pengembangan sistem. Pengembangan sistem teknik (engineering system development). SDLC berfungsi untuk menggambarkan tahapan-tahapan utama dan langkah-langkah dari setiap tahapan yang secara garis besar terbagi dalam empat kegiatan utama, yaitu requirement, analisis, design, programming, testing dan implementasi serta pemeliharaan. Penelitian Software Engineering atau rekayasa perangkat lunak dimaksudkan untuk membantu meningkatkan praktek pengembangan perangkat lunak, sehingga perencanaan 
penelitian membuat ketentuan untuk transisi atau tahapan proses. Penelitian rekayasa perangkat lunak termasuk pada penelitian eksperimental (Andry \& Loisa, 2016). SDLC adalah metode yang perangkat lunak dapat dikembangkan secara sistematis dan yang akan meningkatkan kemungkinan menyelesaikan proyek software dalam batas waktu waktu dan menjaga kualitas produk software sesuai standar. Kerangka Pengembangan Sistem Life Cycle memberikan urutan kegiatan untuk desainer sistem dan pengembang untuk mengembangkan perangkat lunak. Hal ini sering dianggap sebagai bagian dari siklus hidup pengembangan sistem (Mishra \& Dubey, 2013). Prosedur penelitian ini di tujukan pada Gambar 1. Prosedur Penelitian.

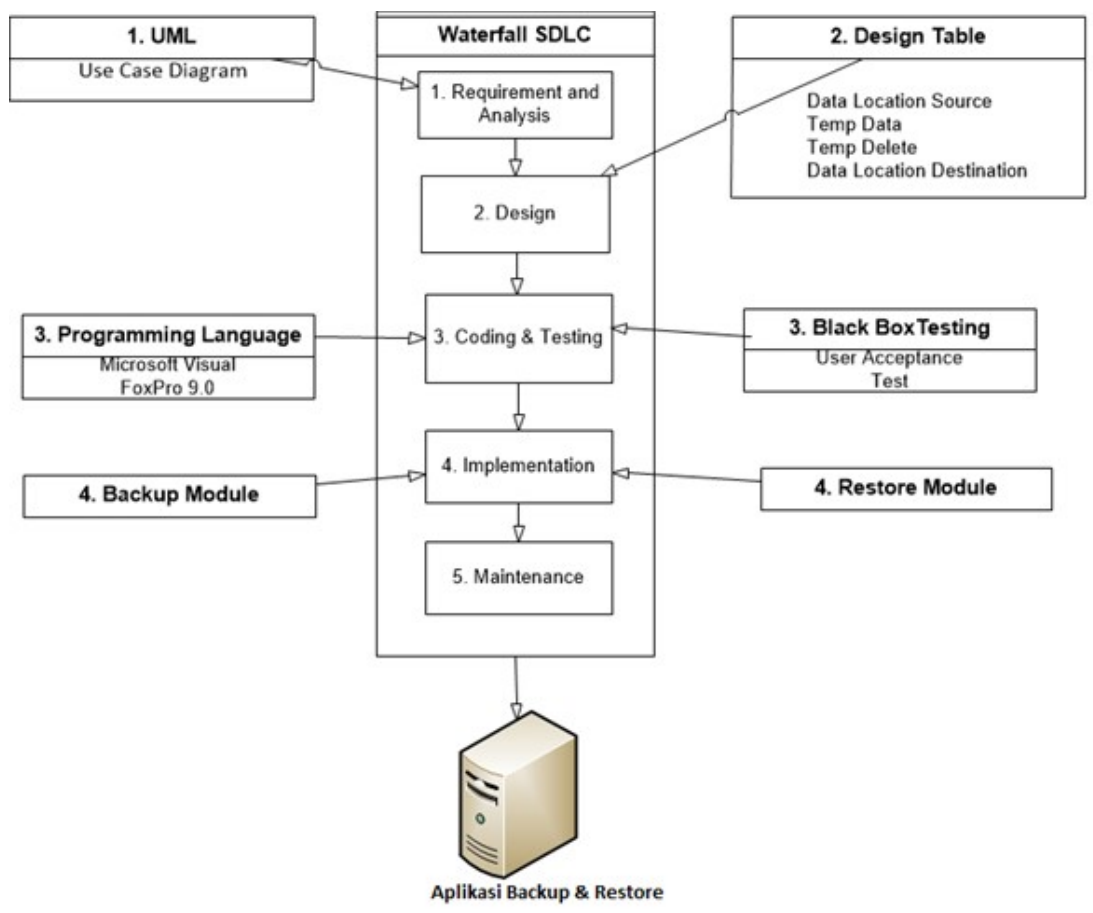

Gambar 1. Prosedur Penelitian

\section{HASIL DAN PEMBAHASAN}

\section{Requirement}

Kebutuhan dari aplikasi ini yaitu user baik individu maupun organisasi terhindar oleh kegagalan sistem atau disaster lainnya, sehingga diharapkan dapat menekan biaya apabila terjadi kerusakan pada file ataupun data di komputer client dan dapat juga menduplikasikan data kedalam media yang terpisah. Data hasil duplikasi tersebut nantinya akan digunakan untuk memulihkan kembali data bila terjadi kerusakan atau kehilangan data. Dalam menganalisa sistem yang diusulkan untuk aplikasi ini adalah user dapat melakukan backup dan restore secara otomatis,

\section{Analisis dengan use case diagram}

Fase analisis adalah tahap untuk memahami detail dari kebutuhan bisnis dan reqirement. Alat dan teknik untuk analisis adalah UML. UML adalah standar bahasa pemodelan umum di bidang ilmu komputer dan rekayasa perangkat lunak. Standar ini dikelola dan dibuat oleh object 
management group (Andry, Agung \& Erlyana, 2016). Use case merupakan bagian utama dari fungsi sistem dan aktor adalah orang atau sistem yang berasal manfaat dari dan eksternal untuk subjek (Dennis, Wixom, Roth \& Roberta, 2012). Pada Gambar 2. Use case diagram Aplikasi Backup dan Restore, diperlihatkan bahwa aktor dalam hal ini adalah pengguna baik individu dan organisasi yang memberi atau menerima sistem, sedangkan use case adalah backup, konfigurasi dan restore, aktor dapat mclakukan backup dan restore, dengan konfigurasi setiap saat, setiap tempat kepada berbagai drive komputer.

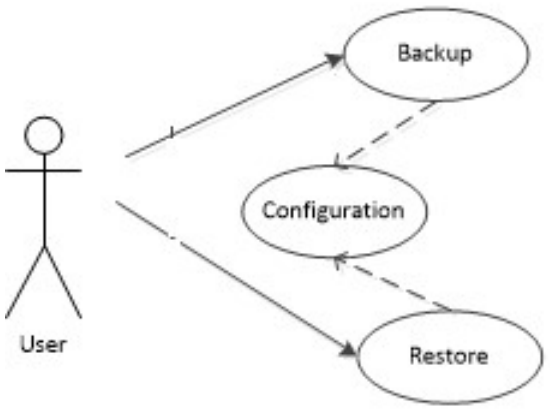

Gambar 2. Use Case Diagram Aplikasi Backup dan Restore

\section{Design Form utama (form backup), form restore dan form konfigurasi}

Membuat project baru, masukkan ke dalam Form1 komponen-komponen yang dibutuhkan sebagai berikut 6 buah label, 4 buah text box, 3 buah button dan 1 buah timer. Untuk langkah selanjutnya, kita akan mengubah semua nilai properties pada masing-masing objek yang ada pada Form1, termasuk nilai properties Form1 itu sendiri. Untuk mengetahui komponen dan properties yang mana yang akan diubah, dan apa nilainya, lihat pada Gambar 3. Design Form Utama.

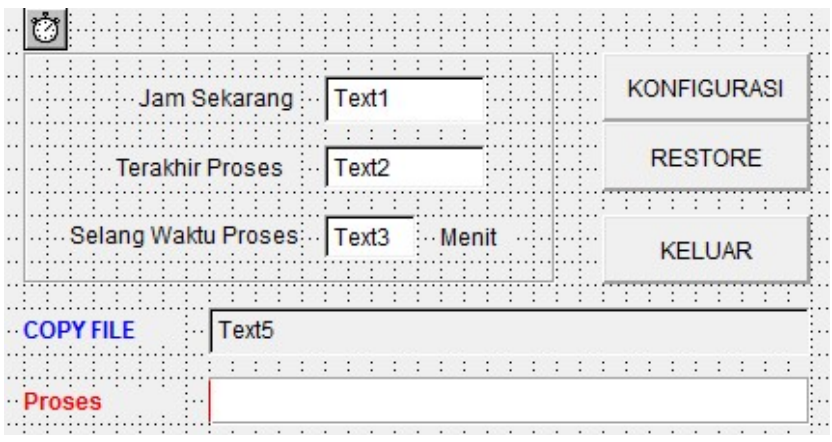

Gambar 3. Design Form Utama

Untuk design form restore, buat di form 2, masukkan ke dalam Form 2 komponen-komponen yang dibutuhkan sebagai berikut 2 buah label, 2 buah text box dan 2 buah button. Langkah selanjutnya, peneliti akan mengubah semua nilai properties pada masing-masing objek yang ada pada form 2, termasuk nilai properties form 2 itu sendiri. Untuk design form konfigurasi, buat di form 3, masukkan ke dalam form 3 komponen-komponen yang dibutuhkan sebagai berikut 1 list 
box, 2 buah label, 2 buah text box dan 4 buah button. Untuk langkah selanjutnya mengikuti langkah form design form restore.

\section{Design table}

Design table data asal digunakan untuk menyimpan informasi data asal atau sumber awal berdasarkan folder maupun file, design table set copy digunakan untuk menyimpan atau copy file atau data tujuan akhir berdasarkan folder maupun file, design table temp data digunakan untuk menyimpan informasi temporary data, karena sewaktu-waktu dapat dirubah folder atau file yang telah diset sebelumnya berdasarkan folder maupun file, design table temp hapus digunakan untuk menghapus informasi file atau folder, karena sewaktu-waktu dapat dirubah folder atau file yang telah diset sebelumnya berdasarkan folder maupun file, design table tujuan digunakan untuk menyimpan informasi data tujuan akhir berdasarkan folder maupun file.

Tabel 1. Design Table

\begin{tabular}{llc}
\hline \multicolumn{1}{c}{ Name } & Type & Width \\
\hline Data Location Source & & \\
\hline Folder name & Character & 200 \\
\hline Set Copy & & \\
\hline Description & Character & 10 \\
\hline Temp Data & & \\
\hline File name & Character & 200 \\
\hline Folder Type & Character & 1 \\
\hline Level & Numeric & 3 \\
\hline Temp Delete & & \\
\hline File name & Character & 200 \\
\hline Folder Type & Character & 1 \\
\hline Level & Numeric & 3 \\
\hline Data Location Destination & & \\
\hline Destination & Character & 2 \\
\hline
\end{tabular}

\section{Coding}

Untuk melaksanakan coding dilakukan dengan bahasa pemprograman yang dilakukan menggunakan Microsoft Visual Foxpro. Karena codingnya begitu banyak tidak bisa ditampilkan semua, hanya beberapa yang akan ditampilkan. Seperti yang diperlihatkan pada gambar 4 . Sebagian Tampilan Coding.

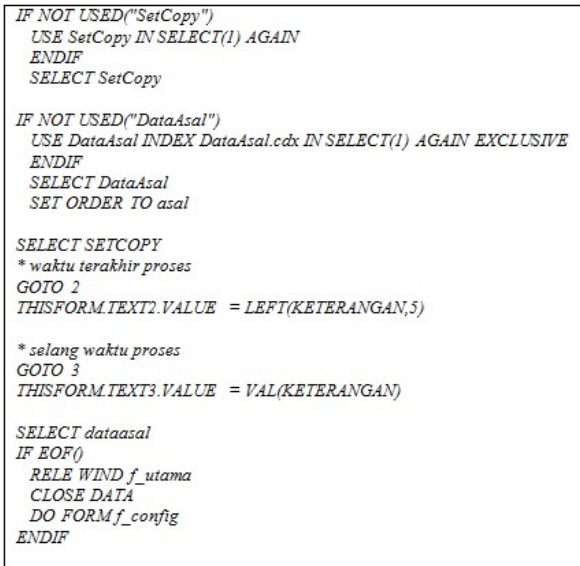

Gambar 4. Sebagian Tampilan Coding 


\section{Testing}

Testing adalah proses menjalankan atau eksekusi suatu program dengan tujuan utama untuk mencari/menemukan kesalahan (error). Dengan kata sederhana, pengujian perangkat lunak adalah kegiatan untuk memeriksa apakah hasil aktual sesuai dengan hasil yang diharapkan dan untuk memastikan bahwa aplikasi bebas cacat. pengujian dilakukan setelah aplikasi selesai dibuat, dengan metode black box testing. Pengujian dilakukan dengan User Acceptance Testing (UAT), dimana hasil keluaran dari tahap ini adalah scenario UAT. Pengujian dilakukan untuk mengetahui dan mengindentifikasi kesalahan yang mungkin terjadi (Saini dan Rai, 2013). Hasil UAT diperlihatkan pada Tabel 2.

Tabel 2. User Acceptance Test

\begin{tabular}{|c|c|c|c|c|c|}
\hline No & $\begin{array}{l}\text { Use case / } \\
\text { Test case }\end{array}$ & Pre-condition & Test steps & Expected Result & Actual Result \\
\hline & & & \multicolumn{3}{|l|}{ Modul $B A C K U P$} \\
\hline B-01 & $\begin{array}{l}\text { Menguji } \\
\text { button } \\
\text { konfigurasi }\end{array}$ & $\begin{array}{l}\text { Pastikan aplikasi } \\
\text { sudah di jalankan }\end{array}$ & Klik button konfigurasi & $\begin{array}{l}\text { Berhasil menampilkan } \\
\text { form konfigurasi }\end{array}$ & $\begin{array}{l}\text { user dapat melakukan } \\
\text { konfigurasi }\end{array}$ \\
\hline B-02 & $\begin{array}{l}\text { Menguji } \\
\text { combobox }\end{array}$ & $\begin{array}{l}\text { User sudah masuk ke } \\
\text { form konfigurasi }\end{array}$ & $\begin{array}{l}\text { Klik combobox, sehingga } \\
\text { ada tampilan mau atau } \\
\text { akan di copy ke drive, } \\
\text { pilihan: A, B, D, E, F dan } \\
\text { H }\end{array}$ & $\begin{array}{l}\text { Berhasil menampilkan } \\
\text { drive, pilihan: A, B, D, } \\
\text { E, F dan H }\end{array}$ & $\begin{array}{l}\text { user dapat melakukan } \\
\text { pilihan drive, untuk } \\
\text { backup kemana yang } \\
\text { diinginkan }\end{array}$ \\
\hline B-03 & $\begin{array}{l}\text { Menguji label } \\
\text { selang waktu }\end{array}$ & $\begin{array}{l}\text { User sudah masuk ke } \\
\text { form konfigurasi }\end{array}$ & $\begin{array}{l}\text { Masukkan angka } 1 \text { hingga } \\
999 \text { di label selang wanku }\end{array}$ & $\begin{array}{l}\text { Berhasil menginput nilai } \\
\text { angka 1-999 }\end{array}$ & $\begin{array}{l}\text { user dapat melakukan } \\
\text { backup dari } 1 \text { menit } \\
\text { hingga } 999 \text { menit }\end{array}$ \\
\hline B-04 & $\begin{array}{l}\text { Menguji } \\
\text { button } \\
\text { Simpan }\end{array}$ & $\begin{array}{l}\text { User sudah masuk ke } \\
\text { form konfigurasi }\end{array}$ & $\begin{array}{l}\text { Pastikan texbox folder } \\
\text { yang akan di copy sudah } \\
\text { tersedia, misal } \\
\text { C: } \backslash 1 . \text { MODUL SAP } \backslash \\
\text { C: } 2 \text {.NGAJAR } 20162 \backslash \\
\text { COPY KE DRIVE D }\end{array}$ & $\begin{array}{l}\text { Berhasil simpan data } \\
\text { dari drive } \mathrm{C} \text { ke drive } \mathrm{D}\end{array}$ & $\begin{array}{l}\text { user dapat melakukan } \\
\text { backup dari drive A, B, } \\
\mathrm{D}, \mathrm{E}, \mathrm{F} \text { dan } \mathrm{H} \text { secara } \\
\text { cross function }\end{array}$ \\
\hline B-05 & $\begin{array}{l}\text { Menguji } \\
\text { button buang } \\
\text { folder }\end{array}$ & $\begin{array}{l}\text { User sudah masuk ke } \\
\text { form konfigurasi }\end{array}$ & $\begin{array}{l}\text { Pastikan texbox folder } \\
\text { yang akan di buang atau } \\
\text { delete sudah tersedia, } \\
\text { misal } \\
\mathrm{C}: \backslash 1 . \text { MODUL SAP } \backslash \\
\mathrm{C}: \backslash 2 . \mathrm{NGAJAR} 20162 \backslash\end{array}$ & $\begin{array}{l}\text { Berhasil buang folder di } \\
\text { text box, missal kita } \\
\text { delete C: } \backslash 2 . \text { NGAJAR } \\
20162 \backslash\end{array}$ & $\begin{array}{l}\text { User dapat delete folder } \\
\mathrm{C}: 12 . \mathrm{NGAJAR} 20162 \backslash \text {, } \\
\text { sehingga di texbox sisa } \\
\mathrm{C}: \backslash 1 . \text { MODUL SAP } \backslash\end{array}$ \\
\hline B-06 & $\begin{array}{l}\text { Menguji } \\
\text { button ambil } \\
\text { folder }\end{array}$ & $\begin{array}{l}\text { User sudah masuk ke } \\
\text { form konfigurasi }\end{array}$ & $\begin{array}{l}\text { Pastikan texbox folder } \\
\text { yang akan di input atau } \\
\text { ambil folder form select } \\
\text { direktori, misal } \\
\text { C: } \backslash 2 . \text { NGAJAR } 20162 \backslash\end{array}$ & $\begin{array}{l}\text { Berhasil ambil folder di } \\
\text { select direktori, sehingga } \\
\text { di text box, akan tampil } \\
\text { C: } \backslash 2 . \text { NGAJAR 20162 }\end{array}$ & $\begin{array}{l}\text { User dapat ambil folder } \\
\text { C: } \backslash 2 \text {.NGAJAR } 20162 \backslash \text {, } \\
\text { sehingga di texbox ada } \\
\text { C: } \backslash 1 \text {.MODUL SAP } \backslash \\
\text { C: } \backslash 2 . \text { NGAJAR } 20162 \backslash\end{array}$ \\
\hline \multirow[t]{2}{*}{ B-07 } & $\begin{array}{l}\text { Menguji } \\
\text { button keluar }\end{array}$ & $\begin{array}{l}\text { User sudah masuk ke } \\
\text { form konfigurasi }\end{array}$ & Klik button keluar & $\begin{array}{l}\text { Berhasil keluar dari form } \\
\text { konfigurasi }\end{array}$ & $\begin{array}{l}\text { User dapat keluar dari } \\
\text { form konfigurasi, } \\
\text { kembali ke form utama }\end{array}$ \\
\hline & & & Modul RESTORE & & \\
\hline R-01 & $\begin{array}{l}\text { Menguji } \\
\text { restore untuk } \\
\text { tanggal }\end{array}$ & $\begin{array}{l}\text { User sudah masuk ke } \\
\text { form modul restore }\end{array}$ & $\begin{array}{l}\text { Menginput tanggal, bulan } \\
\text { dan tahun, dengan angka } \\
\text { yang relevan, misal: } \\
12022017\end{array}$ & $\begin{array}{l}\text { Berhasil melakukan } \\
\text { restore untuk tanggal } \\
12022017\end{array}$ & $\begin{array}{l}\text { User dapat melakukan } \\
\text { restore untuk tanggal } \\
12022017\end{array}$ \\
\hline R-02 & $\begin{array}{l}\text { Menguji } \\
\text { button keluar }\end{array}$ & $\begin{array}{l}\text { User sudah masuk ke } \\
\text { form modul restore }\end{array}$ & Klik button keluar & $\begin{array}{l}\text { Berhasil keluar dari form } \\
\text { restore }\end{array}$ & $\begin{array}{l}\text { User dapat keluar dari } \\
\text { form restore, kembali ke } \\
\text { form utama }\end{array}$ \\
\hline
\end{tabular}

\section{Implementasi dan Maintenance}

Tahap akhir yaitu tahapan dimana siap memberikan aplikasi dan mengimplementasikannya untuk digunakan kepada user. Konfigurasi komputer yang diperlukan untuk implementasi aplikasi ini saat di adakan pengujian pada tabel 3 adalah Hardware terdiri dari Processor Intel CORE 2 DUO, Memory 2 GB, Harddisk 120 GB 5400 Rpm, Harddisk Backup 120 GB 5400 Rpm dan Operating System Windows XP Service Pack 2. Tampilan Form Aplikasi Backup, memperlihatkan jam sekarang adalah waktu yang tertera di komputer, bisa disetting untuk selang 
waktu proses sesuai kebutuhan, bisa 1 menit hingga 999 menit, ada button konfigurasi, digunakan untuk konfigurasi file atau folder yang akan di backup. Pada Gambar 5 Tampilan Form konfigurasi, bisa setting file atau folder yang akan di backup, sebagai contoh diperlihatkan bahwa folder yang akan di backup adalah berasal dari Drive C: 1 .MODUL SAP $\backslash$ dan C; \2.NGAJAR 20162〉, akan di copy ke Drive D: dengan selang waktu 1 menit, backup kaduluwarsa selama 14 hari lalu. Button simpan digunkan untuk menyimpan informasi folder yang akan di copy. Button buang folder digunakan untuk membuang atau delete folder yang akan di copy. Button ambil folder digunakan untuk mengambil file atau folder yang diinginkan. Button keluar digunakan untuk keluar dari halaman konfigurasi.

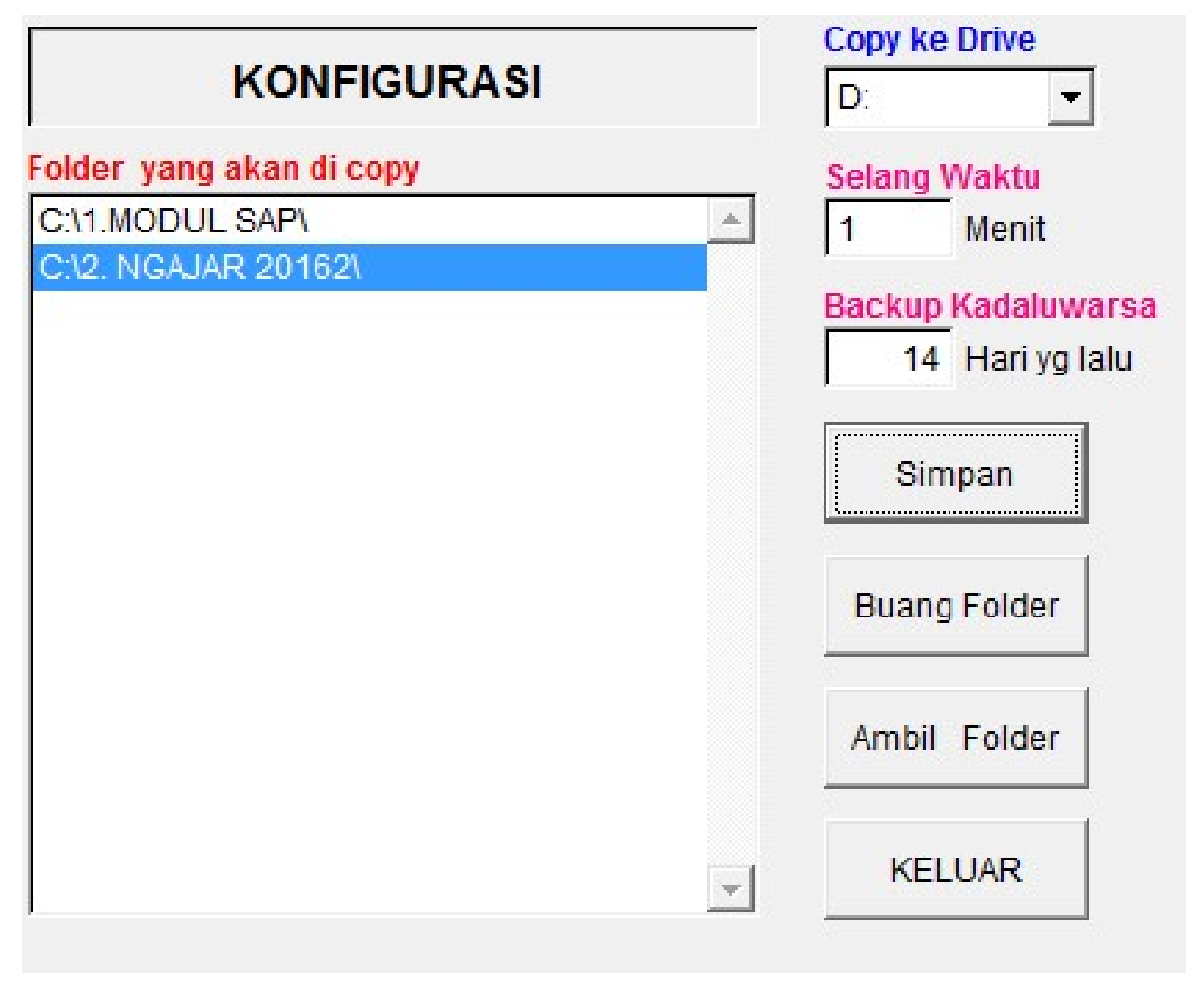

Gambar 5. Tampilan Form Konfigurasi

Tampilan form proses backup folder, adalah dimana proses backup sedang berlangsung, progress backup atau copy diperlihatkan pada proses. Copy file atau backup akan menjadi lama jika file atau folder yang di copy cukup besar, dan juga jika waktu backup selang waktu proses 1 menit, maka setiap 1 menit akan melakukan proses backup, dan akan membebani kinerja komputer user. Pada Gambar 6. Tampilan Form Restore, diperlihatkan proses untuk restore data jika user menginginkan untuk restore file atau folder yang telah dilakukan. 


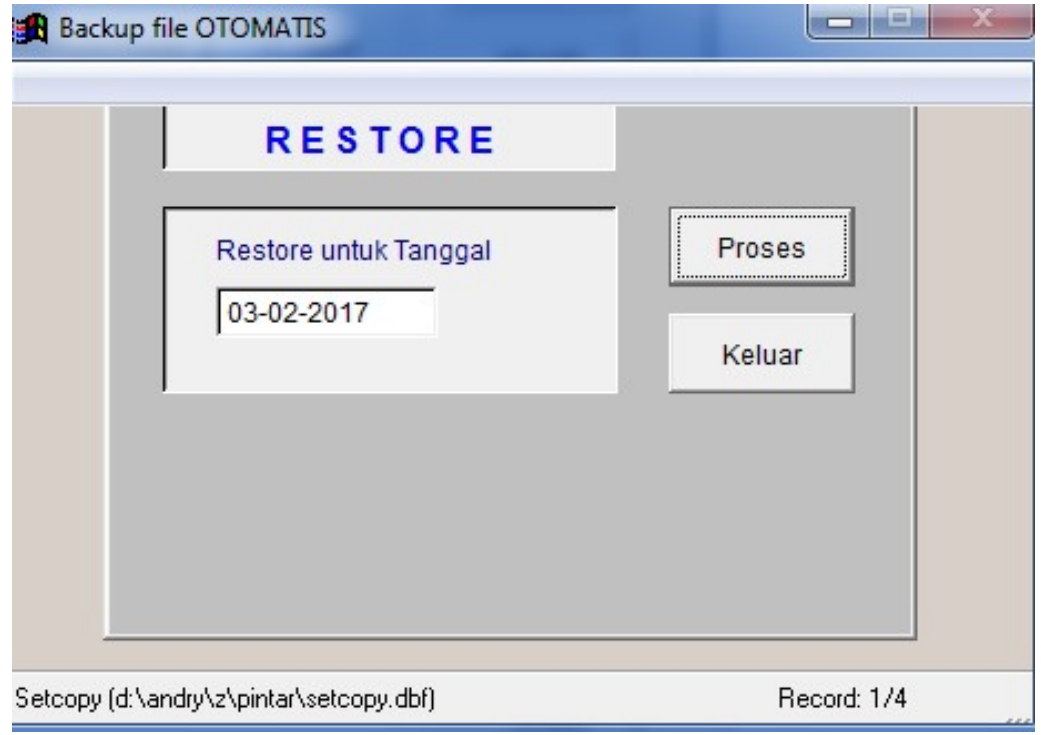

Gambar 6. Tampilan Form Aplikasi Restore

Pengujian selanjutnya akan dilakukan terhadap beberapa file seperti dot doc, dot xls, dot ppt (Ms. Office: Word, Excel, Power point), file extension sound, movie (mp3, Mp4, dll), file extension picture (psd, bmp, jpg, dll), file extension compresed (dot rar \& zip), file extension programming (dot scx, prg, sln, $\mathrm{C}++$, dll) dan kombinasi dari beberapa file dalam satu folder atau pun lebih. Ukuran file yang akan dilakukan pengujian di bagi menjadi tiga kategori yaitu kurang dari $1 \mathrm{MB}, 1 \mathrm{MB}$ sampai dari $99 \mathrm{MB}$ dan $100 \mathrm{MB}$ s/d $10 \mathrm{~GB}$. Yang akan di ukur pada pengujian berbagai jenis file dan ukuran nya adalah waktu backup, untuk melihat berapa lama waktu yang diperlukan untuk backup tersebut dan kualitas backup, apakah file atau folder yang di backup sudah sesuai dan akurat. Hasil implementasi pengujian jenis file dan kualitas backup diperlihatkan pada Tabel 3.

Tabel 3. Hasil Pengujian Jenis File dan Kualitas Backup

\begin{tabular}{|c|c|c|c|c|}
\hline No. & Jenis File & Ukuran File & Waktu Backup & Kualitas Hasil Backup \\
\hline \multirow[t]{3}{*}{1} & \multirow{3}{*}{$\begin{array}{l}\text { File (Ms. Office: Word, Excel, } \\
\text { Power point) }\end{array}$} & Kurang dari $1 \mathrm{MB}$ & 1 detik & Sesuai \\
\hline & & $1 \mathrm{MB}$ s/d $99 \mathrm{MB}$ & 40 detik & Sesuai \\
\hline & & $>100 \mathrm{MB} \mathrm{s} / \mathrm{d} 1 \mathrm{~GB}$ & 11 menit & Sesuai \\
\hline \multirow[t]{3}{*}{2} & \multirow{3}{*}{$\begin{array}{l}\text { File extension sound, movie (dot } \\
\text { mp3, Mp4, dll) }\end{array}$} & Kurang dari $1 \mathrm{MB}$ & 1 detik & Sesuai \\
\hline & & $1 \mathrm{MB} \mathrm{s} / \mathrm{d} 99 \mathrm{MB}$ & 20 detik & Sesuai \\
\hline & & $>100 \mathrm{MB} \mathrm{s} / \mathrm{d} 10 \mathrm{~GB}$ & 6 menit & Sesuai \\
\hline \multirow[t]{3}{*}{3} & \multirow{3}{*}{$\begin{array}{l}\text { File extension picture (dot psd, } \\
\text { bmp, jpg, dll) }\end{array}$} & Kurang dari $1 \mathrm{MB}$ & 1 detik & Sesuai \\
\hline & & $1 \mathrm{MB} \mathrm{s} / \mathrm{d} 99 \mathrm{MB}$ & 30 detik & Sesuai \\
\hline & & $>100 \mathrm{MB} \mathrm{s} / \mathrm{d} 10 \mathrm{~GB}$ & 10 menit & Sesuai \\
\hline \multirow[t]{3}{*}{4} & \multirow{3}{*}{$\begin{array}{l}\text { File extension compresed (dot } \\
\text { rar \& zip) }\end{array}$} & Kurang dari $1 \mathrm{MB}$ & 1 detik & Sesuai \\
\hline & & $1 \mathrm{MB} \mathrm{s} / \mathrm{d} 99 \mathrm{MB}$ & 15 detik & Sesuai \\
\hline & & $>100 \mathrm{MB} \mathrm{s} / \mathrm{d} 10 \mathrm{~GB}$ & 9 menit & Sesuai \\
\hline \multirow[t]{3}{*}{5} & \multirow{3}{*}{$\begin{array}{l}\text { File extension programming (dot } \\
\text { scx, prg, sln, ocx, dll) }\end{array}$} & Kurang dari $1 \mathrm{MB}$ & 1 detik & Sesuai \\
\hline & & $1 \mathrm{MB} \mathrm{s} / \mathrm{d} 99 \mathrm{MB}$ & 50 detik & Sesuai \\
\hline & & $>100 \mathrm{MB} \mathrm{s} / \mathrm{d} 10 \mathrm{~GB}$ & 12 menit & Sesuai \\
\hline
\end{tabular}


Dari hasil tabel 3 diperlihatkan bahwa jenis file yang di backup tidak terpengaruh oleh waktu backup, ukuran file berpengaruh terhadap waktu backup, jadi jika ukuran file makin besar maka waktu backup juga akan semakin bertambah, waktu backup juga berpengaruh terhadap jumlah file atau kuantiti file, makin banyak file, makin lama backup. Kualitas hasil setelah jenis file di backup sudah sesuai dengan harapan artinya tidak ada file yang rusak atau corrupt, ini di buktikan dengan jumlah bytes file yang di backup sama dengan hasil backup.

\begin{tabular}{|c|c|c|}
\hline \multicolumn{2}{|l|}{ Favorites } & Date modified \\
\hline E Desktop & ]3. 20170202 & $02 / 02 / 201721: 44$ \\
\hline Downloads & [1]. 20170203 & 03/02/2017 17:31 \\
\hline \multirow[t]{2}{*}{ 9. Recent Places } & 13. Action coach & $29 / 01 / 201710: 41$ \\
\hline & 13. Andry & $02 / 02 / 201722: 13$ \\
\hline Libraries & 13. Borang SI 2016 & $29 / 01 / 201710: 27$ \\
\hline 豎 Documents & 13. Buku-buku & $31 / 01 / 201710: 13$ \\
\hline d) Music & D. Data Download & $29 / 01 / 201710: 29$ \\
\hline$\Xi$ Pictures & 13. driver printer HP laserjet PRO 400 & $29 / 01 / 201710: 30$ \\
\hline \multirow[t]{2}{*}{ 曙 Videos } & Dinpassing & $31 / 01 / 20178: 55$ \\
\hline & 1. Jurnal Penelitian & $29 / 01 / 201710: 27$ \\
\hline 피 Computer & 1. Kelas 20161 & 03/02/2017 18:05 \\
\hline$\Leftrightarrow$ Local Disk (C:) & 13. Modul SAP & $29 / 01 / 201712: 03$ \\
\hline$\bigoplus$ Local Disk (D:) & 13. Ngajar 20162 & $29 / 01 / 201717: 38$ \\
\hline$\bigoplus$ Local Disk (Z:) & 1. On Going Project & $31 / 01 / 201710: 21$ \\
\hline \multirow[t]{2}{*}{ 13. My Web Sites on MSN } & 13. Personal & $31 / 01 / 201710: 23$ \\
\hline & 13. PKM & $29 / 01 / 201712: 13$ \\
\hline \multirow[t]{5}{*}{ Network } & 13. Smart Learning & $31 / 01 / 201710: 51$ \\
\hline & 13. Story & $29 / 01 / 201710: 36$ \\
\hline & 13. Teaching & $29 / 01 / 201723: 21$ \\
\hline & Back Up. ml & 03/02/2017 17:30 \\
\hline & 䒜 Back Up & 03/02/2017 17:34 \\
\hline
\end{tabular}

Gambar 7. Tampilan Hasil Folder Setelah Backup

Pada Gambar 7. Tampilan Hasil Folder Setelah backup, memperlihatkan bahwa hasil backup berupa folder 20170202, yang artinya bahwa waktu backup dilakukan pada tahun 2017, bulan 02 yaitu bulan February dan tangal 02.

\section{SIMPULAN DAN SARAN}

Simpulan yang didapat dari penelitan ini adalah aplikasi backup dan restore secara automatitasi telah dapat melakukan backup dengan baik, jika melakukan konfigurasi selama 1 menit, dengan file atau folder yang besar, maka akan dapat menghambat kinerja dari computer, karena backup yang dilakukan dengan cara full backup. Dalam hal backup harus dilakukan secara berkala dan berkelanjutan agar supaya tidak kehilangan data atau informasi yang nantinya akan berdampak buat individu maupun organisasi, sehingga terhindar oleh kegagalan sistem atau disaster lainnya. 
Saran penelitian ini adalah akan ada lanjutan yang akan dilakukan dengan beberapa layanan media cloud yang akan dihitung waktu kecepatan dalam hal backup dan restore.

\section{Ucapan Terima Kasih}

Penelitian aplikasi backup dan restore ini terlaksana berkat hibah dana penelitian dosen semester ganjil di tahun akademik 2016/2017 dari Direktorat Pengembangan dan Pengabdian Kepada Masyarakat (P3M) Universitas Bunda Mulia, Jakarta.

\section{REFERENSI}

Aldasouqi \& Awajan, A. (2011). Black Box Backup System. International Journal of Computer Science and Security, Volume 5, Issue 3, 368-375.

Andry, J. F. \& Loisa, J. (2016). The e-Commerce Potential for Home-Based Businesses: A Case Study," Jurnal Ilmiah FIFO P-ISSN 2085-4315 / E-ISSN 2502-8332, Volume VIII, No. 2, 23-27.

Andry, J. F., Agung, H. \& Erlyana, Y. (2016). Management Information System for Order Fulfillment: A Case Study. Proceeding of 9th International Seminar on Industrial Engineering and Management, ISSN : 1978-774X.

Dennis, A., Wixom, B. H., Roth \& Roberta, M. (2012). System Analysis and Design, fifth edition," John Wiley \& Sons, Inc.

Hawkins, S. M, Yen, D. C \& Chou, D. C. (2000). Disaster recovery planning: a strategy for data security. Information Management \& Computer Security, Vol. 8 Issue 5, 222-230. http://dx.doi.org/10.1108/09685220010353150.

Hoong, L, L., \& Marthandan, G. (2014). Critical Dimensions of Disaster Recovery Planning. International Journal of Business and Management, Vol. 9, No. 12, ISSN 1833-3850, EISSN 1833-8119, Published by Canadian Center of Science and Education, 145-158.

Mishra, A. \& Dubey, D. (2013). A Comparative Study of Different Software Development Life Cycle Models in Different Scenarios. International Journal of Advance Research in Computer Science and Management Studies, ISSN: 2321-7782 (Online), Volume 1, Issue 5, 64-69.

Saini, G., \& Rai, K. (2013). An Analysis on Objectives, Importance and Types of Software Testing. International Journal of Computer Science and Mobile Computing, Vol. 2 Issue. 9, 18-23.

Virgona, T. (2010). A Historical Study of the Human Aspects of Disaster Recovery. Paper presented at the Proceedings of the Northeast Business \& Economics Association.

Wijaya, E., Robet \& Robin. (2015). Perancangan Sistem Otomatisasi Backup Data Menggunakan File Transfer Protocol Berbasis Jaringan LAN (Studi Kasus Pada STMIK TIME Medan). Jurnal TIMES, Vol. IV, No. 1, 26-30, ISSN: 2337-3601. 